\title{
Generalized Matching Functions and Resource Utilization Indices for the Labor Market
}

Andreas Hornstein and Marianna Kudlyak

In the years following the Great Recession, the signals for a recovery of the U.S. labor markets were mixed: while the unemployment rate declined to historically low levels, labor force participation rates also declined. This observation raised doubts on the ability of the unemployment rate alone to accurately represent the state of resource utilization in the labor market. ${ }^{1}$ In Hornstein, Kudlyak, and Lange (2014), we therefore proposed an indicator of resource utilization in the labor market, a nonemployment index (NEI), that is more comprehensive than the standard unemployment rate. In this article, we relate our NEI to recent research on frictional unemployment in labor markets and thereby provide a theoretical grounding for the NEI beyond the heuristic justifications for its usefulness in our previous work.

More than 30 years ago, Flinn and Heckman (1983) pointed out that the distinction between those being unemployed and those being out of the labor force (OLF) is not clear cut but a matter of degree. For example, the unemployed, that is, those nonemployed who are actively searching for work, are twice as likely to make the transition to

Andreas Hornstein is a senior advisor at the Federal Reserve Bank of Richmond and Marianna Kudlyak is a senior economist in the Research Department at the Federal Reserve Bank of San Francisco. The authors thank Sean McCrary for excellent research assistance and Marios Karabarbounis, Santiago Pinto, Allen Sirolly, and John Weinberg for helpful comments. The views expressed in this article are those of the authors and not necessarily those of the Federal Reserve Bank of Richmond, the Federal Reserve Bank of San Francisco, or the Federal Reserve System. E-mail: Andreas.Hornstein@rich.frb.org; Marianna.Kudlyak@sf.frb.org.

${ }^{1}$ See, for example, Appelbaum (2014), Yellen (2014), or Irwin (2017).

DOI: http://doi.org/10.21144/eq1020201 
employment within a month than those nonemployed who express a desire to work but do not actively engage in job search activities, and they are three times as likely to make the transition to employment than those who do not even express a desire to work. Thus even though the differences in employment transition probabilities are quantitatively large, they do not suggest a qualitative difference between being unemployed and being OLF. Furthermore, despite the substantially lower employment transition probabilities for OLF, on average, every month twice as many people make the transition from OLF to employment than do from unemployment.

The Diamond-Mortensen-Pissarides search-matching framework interprets new employment as being "produced" by matching job seekers with open positions. ${ }^{2}$ The standard approach assumes a homogeneous search pool, that is, each searcher is equally likely to make the transition to employment. Recent extensions have emphasized the heterogeneous nature of the search pool, that is, the persistent differences in search efficiency between unemployment and OLF, which is reflected in persistent differences of employment transition probabilities, for example, in Veracierto (2011), Diamond (2013), Elsby, Hobijn, and Şahin (2015), Barnichon and Figura (2015), and Hornstein and Kudlyak (2016). Most of this work is done in the context of estimating matching efficiency in the labor market, that is, the extent of labor market frictions. Accounting for heterogeneity in the search pool leads to smaller estimated declines in matching efficiency, in part since heterogeneity introduces systematic positive comovement between total nonemployment and the average search efficiency of the heterogeneous search pool. Within this generalized matching framework, we interpret our proposed NEI as the quality-adjusted measure of the search pool.

This article is structured as follows. We first review the searchmatching framework and how it accounts for changes in average employment transition rates with homogeneous and heterogeneous search pools. We then characterize the pool of nonemployed in the Current Population Survey (CPS) in terms of their average transition rates to employment. Finally, we construct a sequence of NEIs with increasing coverage of the nonemployed, the most comprehensive of them being the NEI proposed in Hornstein et al. (2014). We show how these NEIs fit into a generalized search-matching framework with heterogeneous search pools and study their implications for measured changes in matching efficiency. We should note that there is substantial overlap

\footnotetext{
${ }^{2}$ For example, Pissarides (2000) or Petrongolo and Pissarides (2001).
} 
between this paper and Hornstein et al. (2014), especially as it relates to the characterization of the nonemployed in the CPS.

\section{GENERALIZED MATCHING FUNCTIONS}

The aggregate search and matching function in macro-labor models describes the "production" of hires as a function of the stocks of job seekers and vacancies and an exogenous shift term denoting the aggregate efficiency of the matching process. The standard approach for the search and matching function assumes that the inputs are homogeneous. We augment the standard search and matching function by allowing for fixed heterogeneity across observed groups of job seekers.

\section{The Matching Function with Homogeneous Search}

Consider an economy where unemployed workers need to be matched with open positions. Assume that all workers and open positions are homogeneous, but that for some reason the assignment of unemployed workers to open positions is a time-consuming process. This process is characterized by a matching function,

$$
h=e^{\kappa} v^{\alpha} u^{1-\alpha},
$$

where $h$ is the number of new hires when $v$ vacancies are matched with $u$ unemployed workers, and $\alpha \in[0,1]$ is the elasticity of new hires with respect to vacancies. The matching function is constant returns to scale, that is, if the number of vacancies and unemployed doubles, then the number of new matches also doubles. In fact, the usual specification of the matching function in equation (1) is analogous to a Cobb-Douglas production function where unemployed workers and vacancies are inputs to a process that generates new filled positions. This process may be more or less efficient, and the matching efficiency $\kappa$ reflects the extent of frictions in the labor market. The smaller the matching efficiency, the less efficient the labor market is at matching the unemployed with open positions.

The rate at which unemployed workers make the transition to employment is

$$
\lambda=\frac{h}{u}=e^{\kappa}\left(\frac{v}{u}\right)^{\alpha}=e^{\kappa} \theta^{\alpha},
$$


where the vacancy-unemployment ratio $\theta$ denotes "labor market tightness." ${ }^{3}$ Conditional on the matching elasticity, we can recover the matching efficiency from observations on how long it takes for an unemployed to become employed, that is, the employment transition rate and market tightness,

$$
\kappa=\ln \lambda-\alpha \ln \theta
$$

\section{Heterogeneous Search}

Now suppose that the unemployed differ in their search effectiveness, but that after accounting for these differences, they are all perfect substitutes in the matching function. First assume that there is a finite number of types, $J$, and that each type is endowed with $\rho_{j}$ search units. The total effective search input from all of theses types is

$$
u^{*} \equiv \sum_{j=1}^{J} \rho_{j} u_{j},
$$

and together with the available vacancies the matching function determines total hired search units

$$
h=e^{\kappa} v^{\alpha}\left(u^{*}\right)^{1-\alpha} .
$$

Analogous to the case of homogeneous searchers, the rate at which a search unit will make the transition to employment is then

$$
\lambda^{*}=e^{\kappa}\left(\frac{v}{u^{*}}\right)^{\alpha} .
$$

Since a type $j$ agent is endowed with $\rho_{j}$ search units, her employment transition rate is

$$
\lambda_{j}=\rho_{j} \lambda^{*},
$$

and the differences in search effectiveness account for differences in employment transition rates across types.

We can relate this simple model of search heterogeneity to the baseline model with homogeneous search by explicitly accounting for the average search effectiveness across types,

$$
\bar{\rho}=\sum_{j} \frac{u_{j}}{u} \rho_{j} .
$$

\footnotetext{
${ }^{3}$ We interpret the transitions as occurring continuously over time. In particular, we assume that employment opportunities arrive according to a Poisson process with arrival rate $\lambda$. In this case, a worker who is unemployed at the beginning of the period will be employed at the end of the period with probability $1-e^{-\lambda}$. See also the Appendix.
} 
The employment transition rate per search unit is then

$$
\lambda^{*}=e^{\kappa}(\theta \bar{\rho})^{\alpha},
$$

and the average employment transition rate across all types is

$$
\bar{\lambda}=\sum_{j} \frac{u_{j}}{u} \rho_{j} \lambda^{*}=e^{\kappa} \theta^{\alpha} \bar{\rho}^{1-\alpha} .
$$

Thus, we have to correct for changes in average search effectiveness when we recover the matching efficiency from observations on the average employment transition rate and market tightness,

$$
\kappa=\ln \bar{\lambda}-\alpha \ln \theta-(1-\alpha) \ln \bar{\rho} .
$$

In other words, assuming that all workers in the search pool are homogeneous when they are not conflates changes in matching efficiency with changes in average search effectiveness.

\section{HETEROGENEITY OF NONEMPLOYMENT}

We now briefly describe the components of nonemployment that we use in the construction of our nonemployment index. This section is closely related to Section 1 of Hornstein, Kudlyak, and Lange (2014).

\section{The BLS Classification Scheme}

Among the most widely reported statistics from the Bureau of Labor Statistics (BLS) are the shares of the working-age population who are currently employed, unemployed, and OLF. These shares are estimated using responses from the monthly CPS. A nonemployed respondent is counted as unemployed if she has been actively looking for work in the month preceding the survey week. Those neither employed nor actively looking for work are classified as OLF. Starting with the comprehensive revision of the CPS in 1994, the BLS provides additional detail on the labor market attachment of the nonemployed based on survey responses as to why an individual is not actively looking for work (see Polivka and Miller [1998] for a description of the 1994 CPS revision). The average population shares for the different nonemployment categories in the CPS are listed in Table 1, in columns 1a and 1b. We report the average shares for the years 1994-2007 in column 1a and for the years $2008-16$ in column $1 \mathrm{~b}$. The first sample represents a relatively strong labor market: it includes two expansions, in particular, the late 1990s information technology boom, and the shallow 2001 recession. The second sample is dominated by the 2008-09 Great Recession and represents a relatively weak labor market. 
Table 1 Nonemployment by BLS Categories

\begin{tabular}{|c|c|c|c|c|c|c|}
\hline & \multicolumn{2}{|c|}{ WAP Share } & \multicolumn{4}{|c|}{ Transition Probability } \\
\hline & & & & & $p_{N E}$ & \\
\hline & (1a) & (1b) & $(2 \mathrm{a})$ & $(2 b)$ & $(3 a)$ & $(3 b)$ \\
\hline & & & Unem & ployed & & \\
\hline \multirow[t]{2}{*}{ Short Term } & 2.8 & 3.0 & 30.2 & 24.3 & 26.8 & 28.2 \\
\hline & {$[7.6]$} & {$[7.5]$} & {$[1.00]$} & {$[1.00]$} & {$[1.00]$} & {$[1.00]$} \\
\hline \multirow[t]{3}{*}{ Long Term } & 0.6 & 1.6 & 16.0 & 11.3 & 29.6 & 25.7 \\
\hline & {$[1.6]$} & {$[4.0]$} & {$[0.53]$} & {$[0.47]$} & {$[1.10]$} & [0.91] \\
\hline & \multicolumn{6}{|c|}{ OLF, Want to Work } \\
\hline Marginally attached, & 0.2 & 0.3 & 13.9 & 11.8 & 75.4 & 74.7 \\
\hline discouraged & {$[0.5]$} & {$[0.8]$} & {$[0.46]$} & {$[0.48]$} & {$[2.81]$} & [2.64] \\
\hline \multirow{2}{*}{$\begin{array}{l}\text { Marginally attached, } \\
\text { other }\end{array}$} & 0.4 & 0.4 & 13.7 & 11.0 & 73.8 & 76.5 \\
\hline & {$[1.0]$} & {$[1.0]$} & {$[0.45]$} & {$[0.45]$} & {$[2.75]$} & {$[2.71]$} \\
\hline \multirow[t]{3}{*}{ Other } & 1.7 & 1.7 & 15.4 & 12.8 & 62.1 & 65.5 \\
\hline & {$[4.8]$} & {$[4.2]$} & {$[0.51]$} & {$[0.53]$} & {$[2.32]$} & [2.32] \\
\hline & & OLF, & o Not & Want to & Work & \\
\hline \multirow[t]{2}{*}{ In school, aged 16-24 } & 3.8 & 4.9 & 9.4 & 6.6 & 15.2 & 12.5 \\
\hline & {$[10.3]$} & [12.1] & {$[0.31]$} & {$[0.27]$} & {$[0.57]$} & {$[0.44]$} \\
\hline \multirow{2}{*}{$\begin{array}{l}\text { Not in school, } \\
\text { disabled or retired }\end{array}$} & 7.6 & 7.0 & 7.7 & 7.2 & 18.2 & 20.3 \\
\hline & {$[20.7]$} & {$[17.4]$} & {$[0.26]$} & {$[0.30]$} & {$[0.68]$} & {$[0.72]$} \\
\hline \multirow[t]{2}{*}{ Disabled } & 4.2 & 5.3 & 1.8 & 1.5 & 3.9 & 4.9 \\
\hline & {$[11.6]$} & [13.1] & {$[0.06]$} & {$[0.06]$} & {$[0.14]$} & {$[0.18]$} \\
\hline \multirow[t]{4}{*}{ Retired } & 15.4 & 16.2 & 1.4 & 1.4 & 2.0 & 2.2 \\
\hline & {$[42.1]$} & {$[39.9]$} & {$[0.05]$} & {$[0.06]$} & {$[0.08]$} & [0.08] \\
\hline & \multicolumn{2}{|c|}{ Total } & \multicolumn{4}{|c|}{ Average } \\
\hline & 36.6 & 40.5 & 6.8 & 5.8 & 13.2 & 13.7 \\
\hline
\end{tabular}

Note: For the different nonemployed population groups columns 1 display their average percentage shares in total working-age population (WAP). For columns 1, the terms in square brackets represent the nonemployed groups' percentage shares in total nonemployment. Columns 2 display the groups' average transition probabilities to employment, and columns 3 display their average transition probabilities to any other nonemployment state. For the employment transition probabilities, the terms in square brackets represent the average of transition probabilities when normalized with the transition probability of short-term unemployed. Columns a cover the time period 1994-2007 and columns b the time period 2008-16.

The unemployed can be subdivided based on their reported length of unemployment. Short-term unemployment (STU) covers those who have been unemployed for 26 or fewer weeks, while long-term unemployment (LTU) encompasses those who have been unemployed for more than 26 weeks. Prior to the Great Recession, on average, less than onefifth of all unemployed report more than 26 weeks of unemployment in any one month. But the unemployed represent only one-tenth of the nonemployed. The remaining nine-tenths are OLF.

A little less than one-tenth of the OLF declare that they do want to work, even though they did not actively look for work in the 
previous month. Those in this group who want a job, are available for work, and searched for work within the last year (not the last month) are classified as marginally attached. On average, about one-fourth of those who want work are marginally attached, and there are six times as many unemployed as there are marginally attached respondents. Those marginally attached who did not search for a job during the last month because they were discouraged over job prospects are classified as discouraged. On average, discouraged individuals make up about one-third of the marginally attached. But over nine-tenths of those OLF do not want a job. Among these individuals we can distinguish between those who are retired, disabled, currently in school, and the remainder. On average, the retired and disabled account for about two-thirds of those who do not want work.

Despite the recent decline of unemployment to historically low levels in 2016, in the aftermath of the 2007-09 recession average nonemployment is about 4 percentage points higher than it was prior to the recession. Comparing columns (1a) and (1b) of Table 1, we see that the main drivers of this increase of nonemployment were higher LTU, disability and retirement, and more people in school, whereas the share of those OLF who want to work remained relatively stable. The share of LTU increased to close to one-half of total unemployment and has remained high even though overall unemployment has declined. Some of the increase in disability may be in response to the weak labor market of the Great Recession, but it also reflects the continuation of a positive trend established in prior years. Finally, the increased retirement share reflects the demographics of an aging U.S. population.

\section{Transitions to Employment}

We are motivated to examine broader nonemployment concepts since the distinction between unemployment and OLF is not as sharp as one would think. In fact, from month to month, roughly twice as many individuals transition from OLF to employment as transition from unemployment. We now show that for all of our nonemployment groups, the transition probabilities to employment are positive and that the heterogeneity in these transition probabilities seems to be consistent with the self-reported labor market attachment.

We first use the CPS microdata to construct exit probabilities from nonemployment using the short rotating four-month panels in the CPS. In any month, we observe the labor market status in the current and following month for roughly three-fourths of the sample. Based on the responses to the CPS questions, we group the nonemployed into the nine nonemployment segments discussed above: the two duration 
segments of the unemployed, the three segments of OLF who want a job (marginally attached, discouraged, other), and the four segments of OLF who do not want a job (retired, disabled, in school, not in school). We then construct the transition probabilities into employment or a different nonemployment state for each segment by matching the individual records from the CPS microdata month to month. ${ }^{4}$ The transition probability from a particular segment of nonemployment is the fraction of that segment that exits to employment, $p_{E}$, or to a different segment of nonemployment, $p_{N E}$, from one month to the next.

Table 1, column 2, shows annual averages of the monthly employment transition probabilities for the two unemployment segments and seven OLF segments averaged across 1994-2007 and 2008-16. The chances of becoming employed differ substantially among these groups. The employment probabilities are highest for the short-term unemployed: on average, they have a 30 percent chance of finding a job within a month. Next are the LTU and those OLF individuals who want a job: they are about half as likely to become employed as are the STU. ${ }^{5}$ Then there is the group of those who do not want a job but who are neither retired nor disabled: they are only one-fourth as likely to become employed as are the STU. Finally, there is the group of retired and disabled who are less than one-tenth as likely to become employed as are the STU. ${ }^{6}$

In recessions the employment probabilities tend to fall for all groups, but the ranking of the different groups in terms of their transition probabilities to employment remains the same. ${ }^{7}$ This is also apparent when comparing the pre- and post-Great Recession period, columns $2 \mathrm{a}$ and $2 \mathrm{~b}$ : even though the average transition probabilities are uniformly lower in the post-2008 period, the relative transition probabilities are not that different. Furthermore, the ranking of employment probabilities coincides with the desire to work as stated in the survey: those who actively search tend to have higher transition rates to employment than those who want to work but do not actively look for work, and those who want to work have higher transition rates than those who do not want to work.

\footnotetext{
${ }^{4}$ Our matching procedure follows the algorithms described in Madrian and Lefgren (1999) and Shimer (2012) The CPS microdata fields are available at http://thedataweb.rm.census.gov/ftp/cps_ftp.html\#cpsbasic.

${ }^{5}$ Note that the employment transition probabilities among the marginally attached OLF do not differ much. In particular, there is no reason to single out discouraged workers based on the likelihood of becoming employed again.

${ }^{6}$ See also Fujita (2014).

${ }^{7}$ See Kudlyak and Lange (2014) for graphs of annual averages of monthly job finding rates for the years 1994 to 2013. See also Figures 2 and 3.
} 
Table 1, column 3, shows annual averages of the monthly transition probabilities to a different nonemployment state for the two unemployment segments and seven OLF segments averaged across 1994-2007 and 2008-16. Again, the chances of making the transition to a different nonemployment state differ substantially among these groups, and again the STU stand out. For the STU, the probability of making the transition to a different nonemployment state is slightly lower than the probability of becoming employed, whereas the opposite is true for all other nonemployment states. This is especially noteworthy for those OLF who want to work but are classified as OLF because they do not state that they are actively looking for work. For this group, the probability of exiting to a different nonemployment state is four to five times higher than the probability of becoming employed. It is quite possible that these high probabilities of switching to a different nonemployment state simply mean that individuals in these groups will in the next month state that they are actively looking for work. That being the case, the fact that for all groups except the STU the transition probabilities to some other nonemployment state are higher than the transition probability to employment suggests that looking at the employment transition probability alone as a measure of labor market attachment might be misleading.

We elaborate on the issue of how transition probabilities to employment and some other nonemployment state jointly reflect the transitions to employment in the Appendix. When transitions between employment and nonemployment states take place continuously, the month-to-month transition probabilities that we calculate from the CPS between two points in time reflect this underlying process. In particular, a relatively high transition rate to nonemployment states may mask the true transitions to employment in the employment transition probability. Effectively, the employment transition probability from month to month may appear to be low not because the transition rate to employment is low, but because the transition rate to other nonemployment states with low exit rates to employment is high. In Table 2 , we report the employment transition rates using either employment transition probabilities alone in column 1 or transition probabilities to employment and nonemployment jointly in column $2 .{ }^{8}$ Accounting for the interaction between transitions to employment and other nonemployment states tends to increase the estimated level of employment transition rates, but for all nonemployment segments except for the

\footnotetext{
${ }^{8}$ In the Appendix, we describe how the transition probabilities can be used to recover the transition rates that generate the observed transition probabilities.
} 
Table 2 Employment Transition Rates by BLS Categories

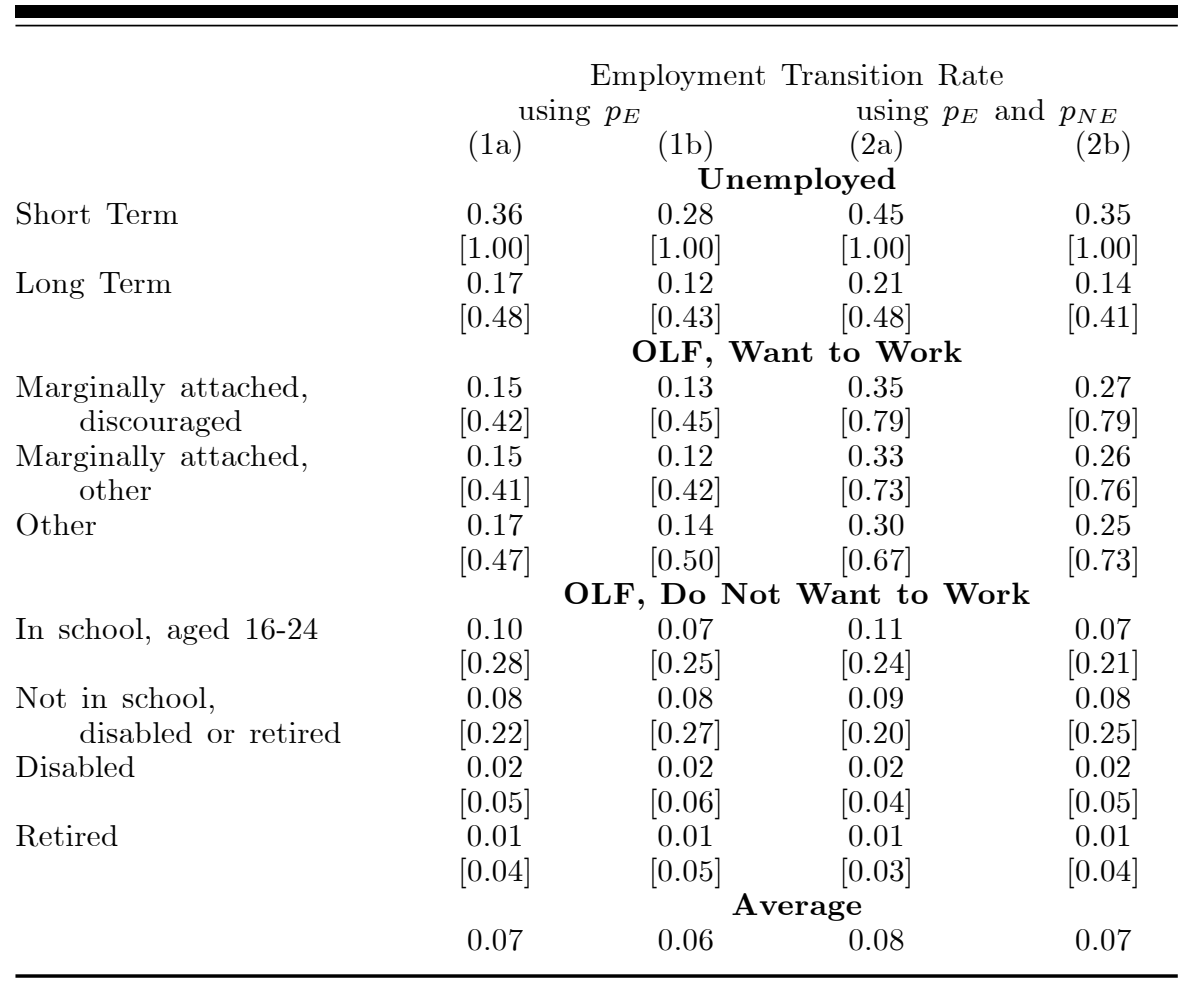

Note: For the different nonemployed population groups, columns 1 display the groups' average employment transition rates calculated from employment transition probabilities only, and columns 2 display their average employment transition rates calculated from transition probabilities to employment and any other nonemployment state. The details of the employment transition rate calculations are described in the Appendix. The terms in square brackets represent the average of transition rates when normalized with the transition rate of the STU. Columns a cover the time period 1994-2007 and b the time period 2008-16.

OLF who want to work it does not affect the employment transition rates relative to the transition rates of the STU.

\section{Heterogeneous Search Pools}

We have motivated the NEI in Hornstein et al. (2014) as a way to capture persistent differences in labor market attachment across groups through their average employment transition rates. The same persistent differences in transitions to employment play an integral part in the generalized matching function with heterogeneous search efficiencies described in Section 1. From this perspective, the important 
Figure 1 Labor Force Status (LFS) of the Nonemployed

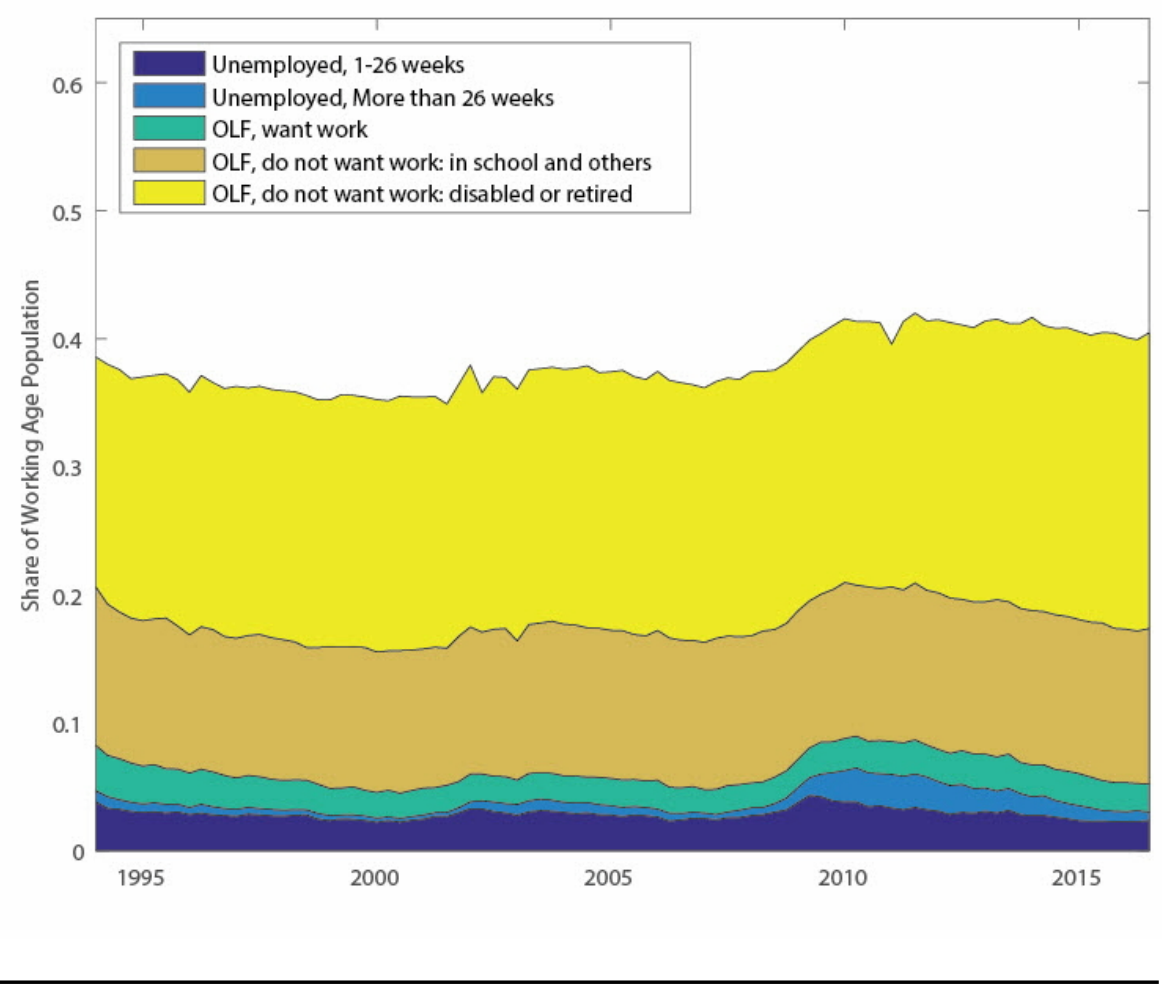

distinctions between the different nonemployment states that enter the NEI and the generalized matching function are (1) short-term unemployment and (2) long-term unemployment, (3) those who are OLF and want to work, (4) those who are OLF, do not want to work, are in school, and others, and (5) those who are OLF, do not want to work, and are disabled or retired. For this aggregation of nonemployment states, the differences of employment transitions across groups clearly dominate the differences within groups. We now describe how the composition and the employment transitions of this "aggregated" search pool change with the business cycle.

In Figure 1, we plot the working-age population shares of the five aggregated nonemployment segments for the period 1994-2016. From this graph it is apparent that for the two recessions in the sample period, 2001 and 2007-09, the nonemployment share is increasing mainly because of increased unemployment. The increase of LTU in the Great Recession is especially striking. Following the recovery from the Great 


\section{Figure 2 LFS Contingent Transition Rates to Employment}

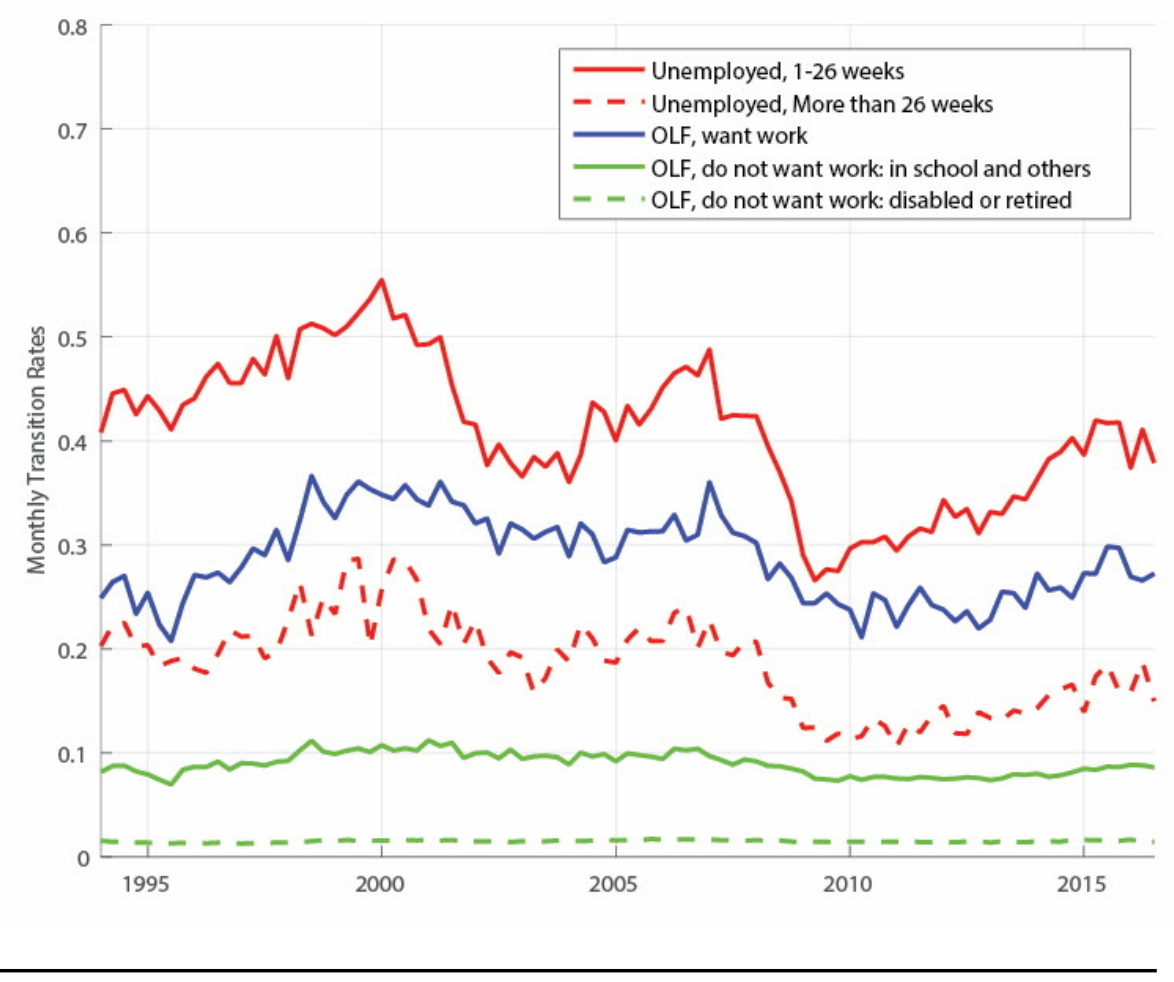

Recession, the decline in unemployment was compensated by an increase of those who are disabled or retired such that the working-age share of nonemployment remained elevated.

In Figure 2, we plot the employment transition rates of the five aggregated nonemployment segments for the period 1994-2016. ${ }^{9}$ The figure reflects the persistent differences in employment transition rates across different nonemployment segments. In particular, employment transition rates across nonemployment segments move together, they decline in recessions and increase in recoveries such that the ranking of transition rates remain unchanged. ${ }^{10}$ This does not preclude different cyclical sensitivities for the transition rates of different nonemployment

\footnotetext{
${ }^{9}$ The "aggregated" employment transition rates are calculated as the nonemployed weighted averages of the employment transition rates calculated using data on exit probabilities to employment and other nonemployment states.

${ }^{10}$ There also appears to be a secular decline in employment transition rates for unemployed and those OLF who want to work.
} 


\section{Figure 3 LFS Contingent Transition Rates Relative to Transition Rates of Short-Term Unemployed}

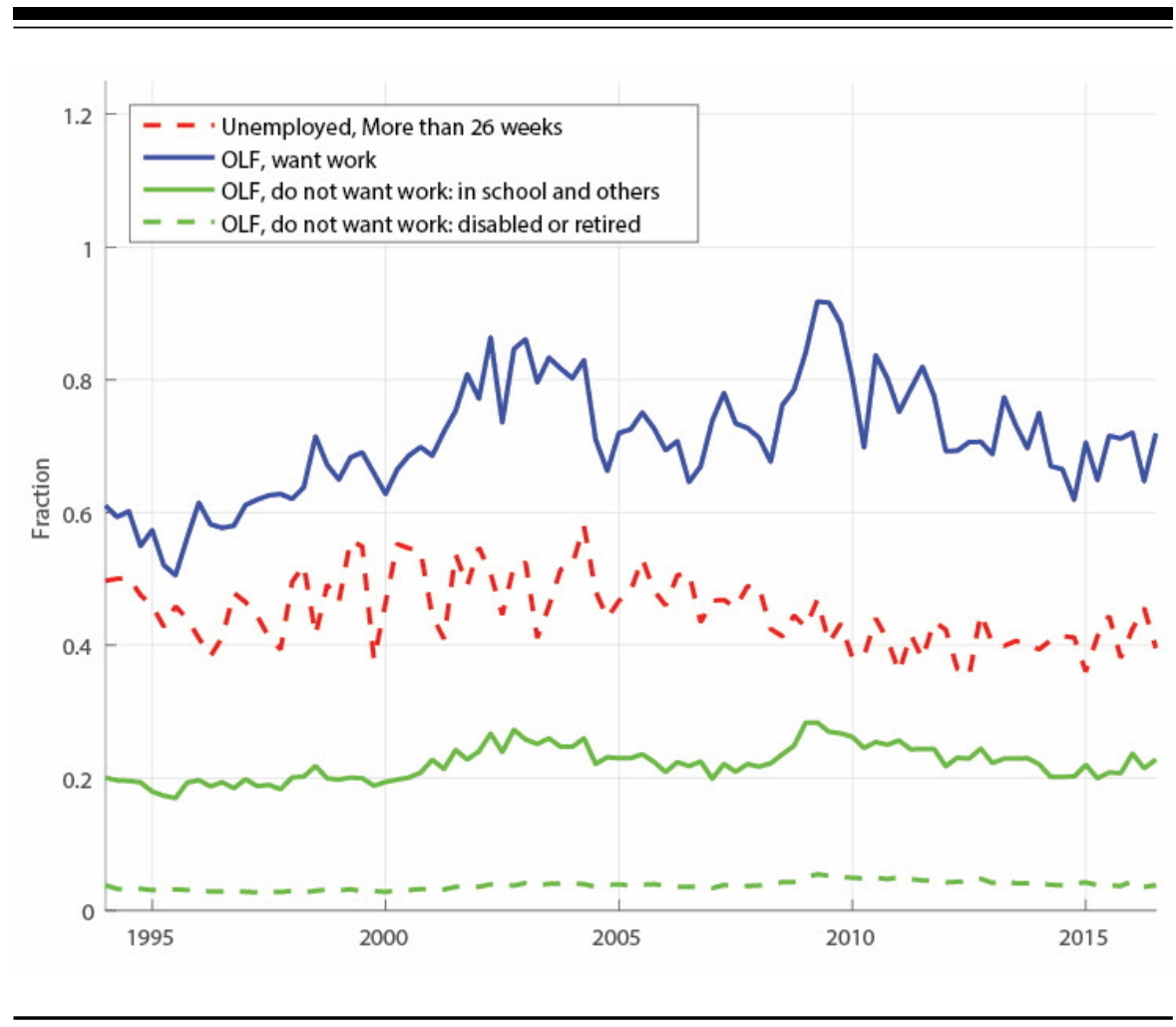

segments, but it appears that the volatility of employment transition rates relative to those of the STU is limited, Figure $3 .^{11}$

In Table 3, we summarize the average properties of working-age population shares and relative employment transitions for our five aggregated nonemployment segments. As we have noted, nonemployment has somewhat increased in the years following the Great Recession, and most of the increase took place among the LTU and the disabled and retired, Table 3 column 1. Even though transitions to employment declined substantially following the Great Recession, the decline affected all nonemployment segments equally, such that the transitions of all segments relative to those of the STU remained quite stable. This stability of relative employment transitions holds independently of how we measure employment transitions, whether it is the straight

${ }^{11}$ Hornstein and Kudlyak (2016) use these different cyclical sensitivities to identify differences in search effort across segments. 
Table 3 Aggregated Nonemployment Categories

\begin{tabular}{|c|c|c|c|c|c|c|}
\hline & \multicolumn{2}{|c|}{ WAP Share } & \multicolumn{4}{|c|}{ Relative Transition } \\
\hline & & & Pro & lity & & \\
\hline & (1a) & $(1 \mathrm{~b})$ & $(2 \mathrm{a})$ & $(2 \mathrm{~b})$ & $(3 \mathrm{a})$ & $(3 b)$ \\
\hline \multicolumn{7}{|l|}{ Unemployed } \\
\hline Short term & 2.8 & 3.0 & 1.00 & 1.00 & 1.00 & 1.00 \\
\hline Long term & 0.6 & 1.6 & 0.53 & 0.47 & 0.48 & 0.41 \\
\hline \multicolumn{7}{|l|}{ OLF, want to work } \\
\hline Marg att and others & 2.3 & 2.4 & 0.50 & 0.51 & 0.69 & 0.74 \\
\hline \multicolumn{7}{|c|}{ OLF, do not want to work } \\
\hline In school and others & 11.3 & 11.9 & 0.27 & 0.29 & 0.21 & 0.23 \\
\hline Disabled or retired & 19.6 & 21.5 & 0.05 & 0.06 & 0.03 & 0.04 \\
\hline
\end{tabular}

Note: For the different nonemployed population groups, columns 1 display their average percentage shares in total working-age population (WAP). Columns 2 display the average of their employment transition probabilities relative to the transition probabilities of the STU, and columns 3 display the average of their employment transition rates relative to the transition rates of the STU when the employment transition rates have been calculated using the exit probabilities to employment and different nonemployment states as described in the Appendix. Columns a cover the time period 1994-2007 and b the time period 2008-16.

employment transition probability, Table 3 column 2 , or the employment transition rate calculated from the exit probabilities to employment and a different nonemployment state, Table 3 column 3. In Section 2 , we have argued that the employment transition rate represents a better measure of employment transitions, and for the following, we will use the average employment transition rates for the full sample, the average of Table 3 column $3 \mathrm{a}$ and column $3 \mathrm{~b}$, as our measure of the relative quality of the different nonemployment segments. ${ }^{12}$

\section{MATCHING EFFICIENCY AND THE NEI}

We now use the information on relative employment transition rates to construct measures of quality-adjusted search input for a matching function with heterogeneous search efficiencies as described in Section 1, equation (4). These quality-adjusted search input measures correspond to the nonemployment index we proposed in Hornstein et al. (2014). We then show that measures of matching efficiency for generalized matching functions that account for heterogeneity are less volatile than the matching efficiency measures derived from standard

\footnotetext{
${ }^{12}$ Using average relative transition rates from the pre-2008 period does not change the results.
} 
Figure 4 NEI: A Measure of Quality-Adjusted Search Effort

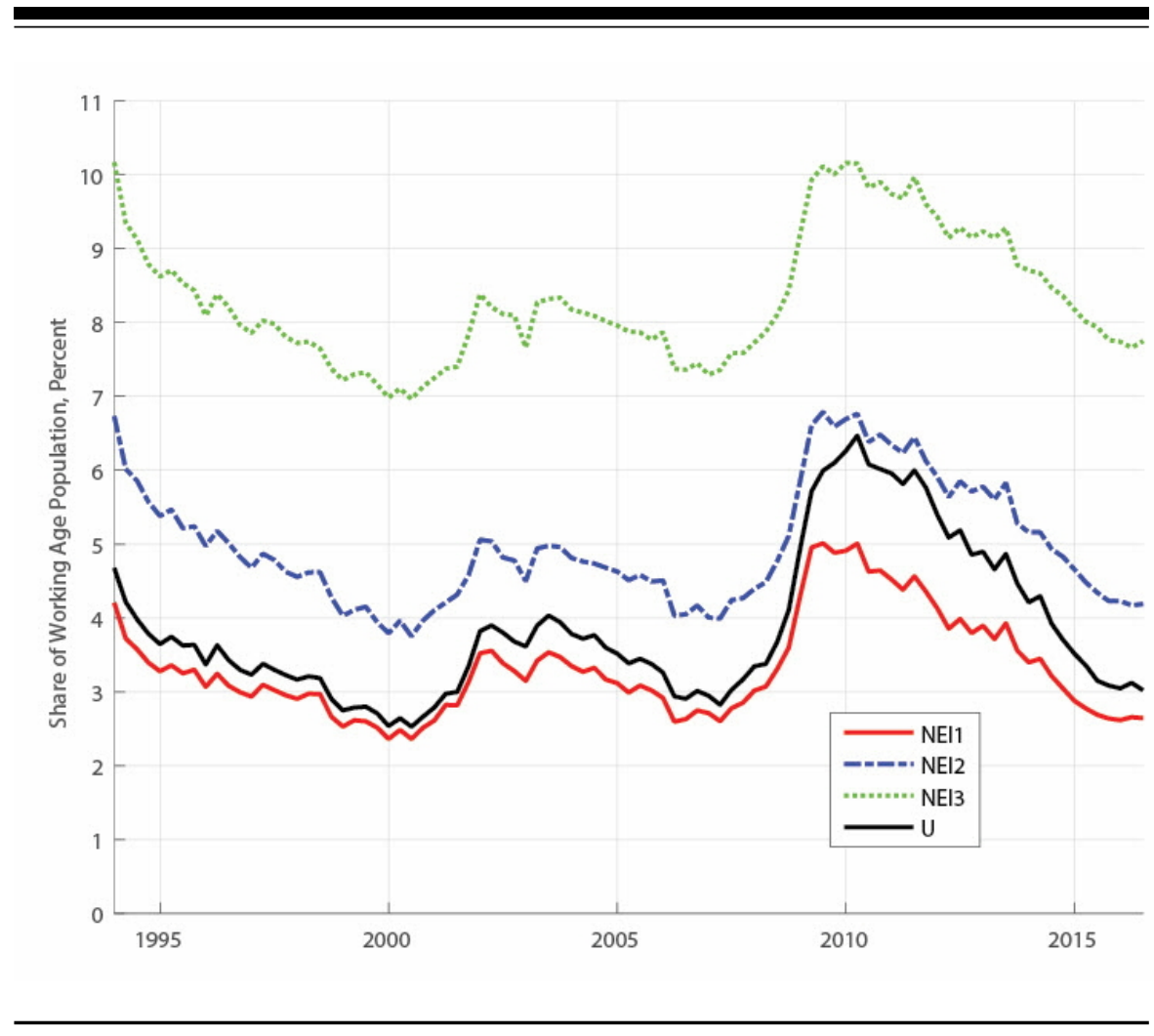

matching functions that assume homogeneous search and are limited to the unemployment pool.

We proceed by gradually expanding our definition of the search pool. For the first definition (NEI1), we take the weighted sum of STU and LTU, where STU receives a weight of 1 and LTU receives a weight of 0.46. The weight of LTU is its average employment transition rate relative to STU or, using the heterogeneous search framework

$$
\frac{\lambda_{L T U}}{\lambda_{S T U}}=\frac{\rho_{L T U}}{\rho_{S T U}}=\rho_{L T U},
$$

since $\rho_{S T U} \equiv 1 .{ }^{13}$ For the second definition (NEI2), we add the OLF who want to work with a weight of 0.71 to NEI1. Finally, for the third

\footnotetext{
13 Assigning a weight of one to STU is a normalization. Choosing a different weight for STU while maintaining the relative weights between the different groups affects the scale of the NEI but not its cyclical properties.
} 
definition (NEI3), we add the OLF who are at school with a weight of 0.24 and the disabled and retired with a weight of 0.04 to NEI2. The working-age population shares of the three quality-adjusted search pools are displayed in Figure 4. For comparison, we have also added the working-age population share of the unweighted unemployed $(\mathrm{U})$, which represents the standard measure of unemployment.

By construction, the level of the NEIs is increasing as we expand the coverage of nonemployment. In particular, once we include weighted OLF (NEI2 and NEI3), the levels of the NEIs are larger than for the standard measure of unemployment U. But note that the NEIs tend to be less volatile than the standard measure of unemployment, that is, they increase less in recessions than does the standard measure of unemployment. Furthermore, like the unemployment rate, all NEIs have essentially returned to their pre-Great Recession lows.

The proposed NEIs represent the quality-adjusted input to a generalized matching function that accounts for heterogeneity in search efficiencies across types. Following the discussion in Section 1, we can decompose changes in the average employment transition rate across all nonemployment segments included in an NEI, $\bar{\lambda}$, into changes coming from market tightness, $\theta$, average search pool quality, $\bar{\rho}$, and aggregate matching efficiency, $\kappa$, equation (7). We construct market tightness, that is, the ratio of vacancies to the unweighted sum of nonemployment segments in the NEI, using the adjusted help-wanted index (HWI) from Barnichon (2010) for vacancies and posted job openings from JOLTS. ${ }^{14}$ In Figure 5, we plot the average employment transition rates (A), market tightness (B), average quality (C), and matching efficiency (D) for our three NEI definitions. ${ }^{15}$ For comparison, we also plot average quality and matching efficiency for the standard measure of unweighted unemployment.

The average employment transition rate declines in recessions and increases in expansions, Figure 5.A. This property of the average transition rate simply reflects the same countercyclical pattern for all of the component transition rates. As we expand the coverage of the search pool, the average transition rate becomes less volatile. ${ }^{16}$ In

${ }^{14}$ The HWI index is available from the 1970s on, whereas JOLTS data are available only from $2000 \mathrm{on}$. The shift in job advertising from print media to web-based means that the HWI may not be consistent over time. Barnichon (2010) corrects for these structural changes in the HWI series in a way such that the HWI lines up with the JOLTS job openings in mid-2000, and we splice the two series in 2006.

${ }^{15}$ We plot the $\log$ of each series and normalize each series to zero at the beginning of the sample.

${ }^{16}$ The level of the average employment transition rate also declines as we expand the coverage of the search pool, but this is not apparent from Figure 5.A since we have normalized each series to zero at the beginning of the sample. 


\section{Figure 5 Components of the Average Employment Transition Rate}
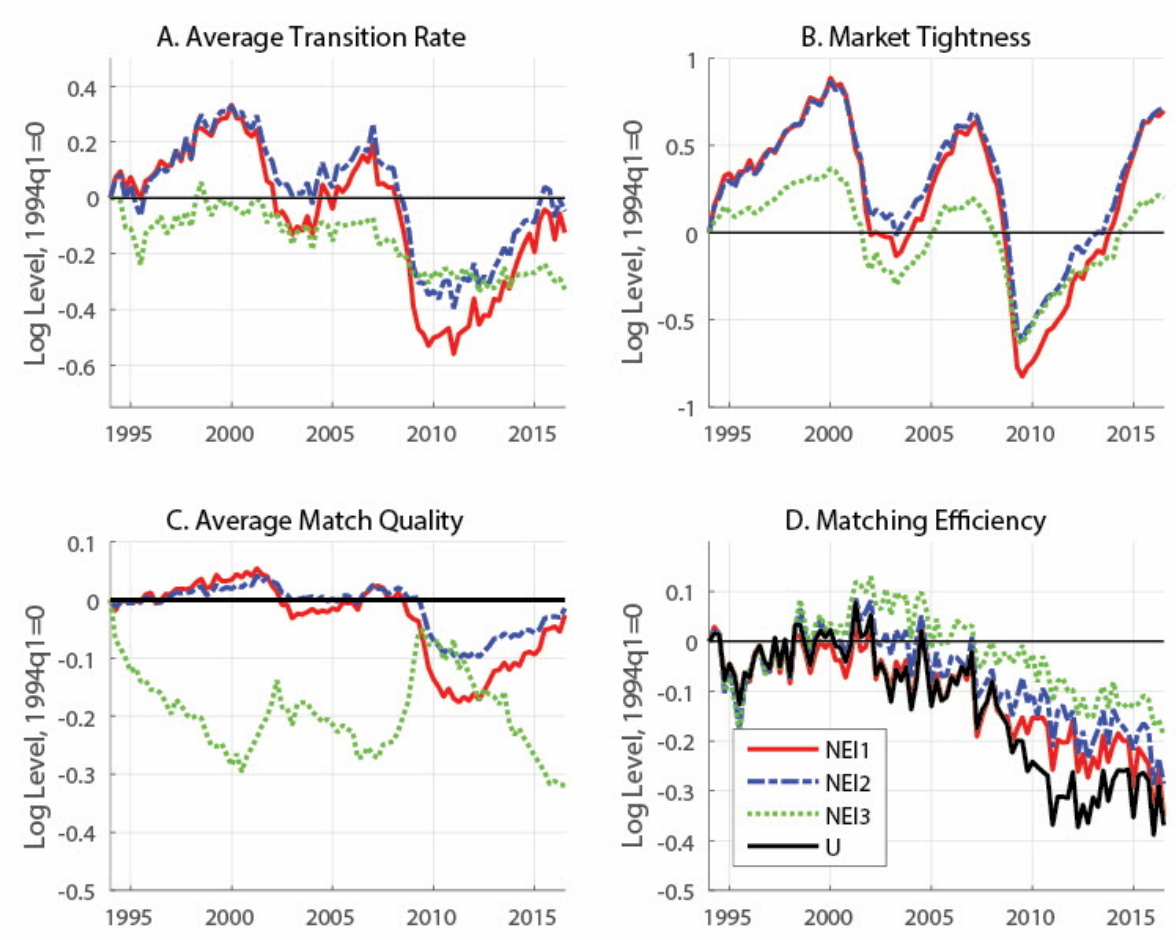

particular, the average transition rate declines less in recessions. This is because relative to the employment transition rates of the unemployed, the transition rates of the OLF (want work) decline less in recessions (NEI2 versus NEI1), as do the transition rates of the OLF (do not want work) (NEI3 versus NEI2). Furthermore, the unemployed with highly volatile transition rates represent a relatively small share of NEI3.

Market tightness has the same cyclical pattern as the average employment transition rate: it declines in recessions and increases in expansions, Figure 5.B. This feature reflects the fact that in recessions vacancy postings decline and nonemployment increases. The volatility of market tightness also declines as we expand the coverage of the search pool, and this reflects the fact that unweighted, like weighted, (NEI) nonemployment becomes less volatile as we expand the coverage of the search pool, Figure 4. 
In the standard matching framework with homogeneous search, average quality is constant. In the generalized matching framework with heterogeneous search, average quality reflects the composition of the search pool, Figure 5.C. For example, average quality for qualityadjusted unemployment (NEI1) declines in recessions because the share of LTU with relatively low search efficiency is increasing in recessions. Average quality continues to decline in recessions for the search pool (NEI2) that includes OLF (want work), but the magnitude of the decline is reduced since the weight of OLF (want work) is more similar to STU than it is to LTU. For the broadest definition of the search pool (NEI3) that includes OLF (do not want work), average quality increases in recessions. This is unlike what we see for the two narrower definitions of the search pool and occurs because the share of OLF (do not want work) in total nonemployment declines in recessions and both components of OLF (do not want work) receive smaller quality weights than all other nonemployment components in the search pool.

Finally, matching efficiency represents the residual component that, together with market tightness and average quality, accounts for the movements in average employment transition rates. In Figure 5.D, we use equation (7) to construct measures of matching efficiency for the different search pool definitions. We assume that the matching elasticity is $\alpha=0.35$, a value consistent with estimates from Barnichon and Figura (2015) and within the range of reported matching elasticities from Petrongolo and Pissarides (2001). We start with the matching efficiency calculated for the standard search pool definition with homogeneous unemployment (U). For this measure, the decline in matchingelasticity weighted market tightness accounts for some of the decline in average transition rates, but with no change in average quality a significant decline in matching efficiency remains. Once we account for heterogeneity in the search pool of unemployed (NEI1), average quality declines in recessions and less of a decline in matching efficiency is required. Once we include OLF (want work) in the search pool (NEI2), the average transition rate and market tightness both decline less in recessions, but the change is more pronounced for the average transition rate such that a smaller decline of matching efficiency is required. Finally, for the most comprehensive definition of the search pool (NEI3), which includes OLF (do not want work), average employment transition rates are even less volatile relative to market tightness and average quality increases in recessions such that substantially smaller declines in matching efficiency occur during recessions. 


\section{CONCLUSION}

We have reviewed the evidence on heterogeneity among the nonemployed in the CPS with respect to their likelihood of making the transition to employment within a month, and we have shown that while the differences between the groups that are most and least likely to make the transition to employment are quantitatively substantial, there is also a gradual transition between the groups at the extremes. We have then shown that the NEI proposed in Hornstein et al. (2014) represents the quality-adjusted search input of a generalized matching function that accounts for heterogeneity in search efficiency across the search pool. Finally, expanding the coverage of the search pool at the same time one accounts for heterogeneity in search effort reduces the measured decline in matching efficiency associated with the Great Recession. In other words, for an appropriately defined broader concept of nonemployment, the efficiency of the U.S. labor market has not declined as much as would be suggested by standard measures of unemployment.

\section{APPENDIX}

Data for the population shares and employment transition rates for nonemployment by reason are constructed from the monthly CPS micro datasets as in Kudlyak and Lange (2014). All data are seasonally adjusted using the procedure proposed by Watson (1996). We deviate from Hornstein et al. (2014) in the construction of the employment transition rates in order to account for the possibility that the nonemployment state may change not only because a nonemployed worker makes the transition to employment, but also because she may just make the transition to a different nonemployment state. Both transition rates will be reflected in the transition probability to employment, but from a matching function perspective we are mainly interested in the transition rate to employment.

Take a group with nonemployment status $j$. Assume that transitions to employment or a different nonemployment state arrive continuously according to Poisson processes with arrival rates $\lambda_{j E}$ and $\lambda_{j N}$, respectively. Then the probability that within a month a member will 
exit nonemployment state $j$ for employment is

$$
p_{j E}=\int_{0}^{1} \underbrace{e^{-\lambda_{j N} \tau}}_{\text {no exit to } N \text { by } \tau} \underbrace{\left(\lambda_{j E} e^{-\lambda_{j E} \tau}\right)}_{\text {transition to } E \text { at } \tau} d \tau=\lambda_{j E} \int_{0}^{1} e^{-\left(\lambda_{j N}+\lambda_{j E}\right) \tau} d \tau,
$$

ignoring the possibility that somebody will flow back into state $j$ in the same month. ${ }^{17}$ We can simplify this expression and apply the same procedure to the exit probability to a different nonemployment state, and we get

$$
\begin{aligned}
p_{j E} & =\frac{\lambda_{j E}}{\lambda_{j E}+\lambda_{j N}}\left[1-e^{-\left(\lambda_{j E}+\lambda_{j N}\right)}\right] \\
p_{j N} & =\frac{\lambda_{j N}}{\lambda_{j E}+\lambda_{j N}}\left[1-e^{-\left(\lambda_{j E}+\lambda_{j N}\right)}\right] .
\end{aligned}
$$

We have data on the monthly transition probabilities to employment, $p_{j E}$, or a different nonemployment state, $p_{j N}$. We can recover the transition rates $\lambda$ from the transition probabilities $p$ as follows

$$
\begin{aligned}
\lambda_{j N} & =-\frac{\log \left(1-p_{j E}-p_{j N}\right)}{\left(1+p_{j E} / p_{j N}\right)} \\
\lambda_{j E} & =-\frac{\log \left(1-p_{j E}-p_{j N}\right)}{\left(1+p_{j E} / p_{j N}\right)} \\
& =-p_{j E} \frac{\log \left(1-p_{j E}-p_{j N}\right)}{\left(p_{j E}+p_{j N}\right)} .
\end{aligned}
$$

For $p_{j N}$ small relative to $p_{j E}$ we have

$$
\lambda_{j E} \approx-\log \left(1-p_{j E}\right)
$$

that is, we can limit attention to the employment transition probabilities. Note that the exit rates are defined on the unit interval, which represents one month. So we are calculating monthly exit rates.

\footnotetext{
17 Shimer (2012) proposes a procedure that recovers continuous time exit rates allowing for the possibility that an agent who exits a state returns to the state within the unit of observation. His procedure uses information from the complete transition matrix covering transitions between all labor market states.
} 


\section{REFERENCES}

Appelbaum, Binyamin. 2014. "Still Needed: Millions of Jobs." New York Times, April 4.

Barnichon, Regis. 2010. "Building a Composite Help-Wanted Index. Economics Letters 109 (December): 175-78.

Barnichon, Regis, and Andrew Figura. 2015. "Labor Market Heterogeneity and the Aggregate Matching Function." American Economic Journal: Macroeconomics 7 (October): 222-49.

Diamond, Peter. 2013. "Cyclical Unemployment, Structural Unemployment." IMF Economic Review 61 (August): 410-55.

Elsby, Michael W.L., Bart Hobijn, and Ayşegül Şahin. 2015. "On the Importance of the Participation Margin for Labor Market Fluctuations." Journal of Monetary Economics 72 (May): 64-82.

Flinn, Christopher J., and James J. Heckman. 1983. “Are Unemployment and Out of the Labor Force Behaviorally Distinct Labor Force States?" Journal of Labor Economics 1 (January): $28-42$.

Fujita, Shigeru. 2014. "On the Causes of Declines in the Labor Force Participation Rate." Federal Reserve Bank of Philadelphia Research Rap Special Report (February).

Hornstein, Andreas, and Marianna Kudlyak. 2016. "Estimating Matching Efficiency with Variable Search Effort." Federal Reserve Bank of Richmond Working Paper 16-13R (December).

Hornstein, Andreas, Marianna Kudlyak, and Fabian Lange. 2014. "Measuring Resource Utilization in the Labor Market." Federal Reserve Bank of Richmond Economic Quarterly 100 (First Quarter), 1-21.

Hornstein, Andreas, Marianna Kudlyak, Fabian Lange, and Tim Sablik. 2014. "Does the Unemployment Rate Really Overstate Labor Market Recovery?" Federal Reserve Bank of Richmond Economic Brief 14-06 (June).

Irwin, Neil. 2017. "Trump Said the Unemployment Rate Wasn't Real. Here Are Some Other Options." New York Times. February 3.

Kudlyak, Marianna, and Fabian Lange. 2014. "Measuring Heterogeneity in Job Finding Rates among the Nonemployed Using Labor Force Status Histories." Federal Reserve Bank of Richmond Working Paper 14-18 (October). 
Madrian, Brigitte C., and Lars John Lefgren. 1999. "A Note on Longitudinally Matching Current Population Survey (CPS) Respondents." Cambridge, Mass.: National Bureau of Economic Research Technical Working Paper 247 (November).

Petrongolo, Barbara, and Christopher A. Pissarides. 2001. "Looking into the Black Box: A Survey of the Matching Function." Journal of Economic Literature 39 (June): 390-431.

Pissarides, Christopher A. 2000. Equilibrium Unemployment Theory, 2nd edition. Cambridge, Mass.: MIT Press.

Polivka, Anne E., and Stephen M. Miller. 1998. "The CPS After the Redesign: Refocusing the Economic Lens." In Labor Statistics Measurement Issues; Studies in Income and Wealth, vol. 60, edited by John Haltiwanger, Marilyn E. Manser, and Robert Topel. Chicago: University of Chicago Press, 249-89.

Shimer, Robert. 2012. "Reassessing the Ins and Outs of Unemployment." Review of Economic Dynamics 15 (April): $127-48$.

Veracierto, Marcelo. 2011. "Worker Flows and Matching Efficiency." Federal Reserve Bank of Chicago Economic Perspectives 35 (Fourth Quarter): 147-69.

Watson, Mark W. 1996. "Comment on 'Is Seasonal Adjustment a Linear or Nonlinear Data-Filtering Process." Journal of Business and Economic Statistics 14 (July): 394-6

Yellen, Janet L. 2014. "Labor Market Dynamics and Monetary Policy." Speech at the Federal Reserve Bank of Kansas City Economic Symposium, Jackson Hole, Wyo., August 22. 